Aletria, Belo Horizonte, v. 28, n. 4, p. 103-117, 2018

(c) (1)

\title{
Feições do racismo no conto "Pixaim", de Cristiane Sobral
}

\section{Racism Features in the Tale "Pixaim", by Cristiane Sobral}

\author{
Franciane Conceição da Silva \\ Pontifícia Universidade Católica de Minas Gerais (PUC-Minas), Belo Horizonte, \\ Minas Gerais / Brasil \\ Capes \\ francyebano14@hotmail.com
}

Resumo: O presente artigo analisa o conto "Pixaim", extraído da coletânea Espelhos, miradouros, dialéticas da percepção (2011), da escritora Cristiane Sobral. No conto encena-se a relação conflituosa entre a protagonista negra e a sua mãe branca. Nesta relação, o ato da mãe de submeter o cabelo da filha a diversos processos de alisamento, tentando amansar a rebeldia dos fios crespos, metaforiza a dificuldade da mulher branca em aceitar o fenótipo da criança negra. No decorrer da análise do conto, procuramos compreender as estratégias narrativas utilizadas pela autora para encenar a violência do racismo que se manifesta no contexto de uma família interracial. Aprofundamos a análise da temática abordada na narrativa de Sobral, recorrendo a estudos de diferentes áreas do saber, destacando-se a Psicologia e a Psicanálise.

Palavras-chave: literatura afro-brasileira; Cristiane Sobral; Pixaim; racismo; família interracial.

Abstract: This article analyzes the story "Pixaim", extracted from the collection Espelhos, miradouros, dialéticas da percepção (2011), by Cristiane Sobral. In this story, there is a conflict between the black protagonist and her white mother. In this relationship, the act of the mother's subjection of her daughter's hair to several straightening processes, trying to tame the rebellion of the curly strands, metaphorizes the struggle of white women to accept the phenotype of black children. In this analysis, we tried to understand the narrative strategies used by the author to stage the violence of racism that is manifested in the context of an interracial family. We aimed at an in- 
depth investigation of the subject approached in the narrative of Sobral, resorting to studies of different fields of knowledge, especially, Psychology and Psychoanalysis.

Keywords: Afro-Brazilian literature; Cristiane Sobral; Pixaim; racism; interracial family.

A violência de alisar os cabelos crespos, num gesto de tentar se adequar ao padrão de beleza eurocêntrico, é uma prática recorrente entre a população negra, principalmente entre as mulheres negras. Em seu ensaio "Alisando o nosso cabelo", a teórica afro-americana bell hooks fala sobre essa relação conflituosa das mulheres negras com os seus cabelos crespos:

Conversando com grupos de mulheres em diversas cidades universitárias e com mulheres negras em nossas comunidades, parece haver um consenso geral sobre a nossa obsessão com o cabelo, que geralmente reflete lutas contínuas com a auto-estima e a auto-realização. Falamos sobre o quanto as mulheres negras percebem seu cabelo como um inimigo, como um problema que devemos resolver, um território que deve ser conquistado. Sobretudo, é uma parte de nosso corpo de mulher negra que deve ser controlado. ${ }^{1}$

Considerando a reflexão proposta pela teórica e ativista bell hooks, podemos dizer que a relação de conflito que grande parte das mulheres negras estabelece com o seu cabelo crespo se dá em consequência do processo de socialização destas. Nesse processo, as mulheres negras são levadas a internalizarem a ideia de que a textura do seu cabelo crespo é feia e só serão consideradas bonitas e, socialmente aceitas, se processarem os cabelos quimicamente, no intuito de tentar deixá-los o mais parecido possível com os cabelos das mulheres brancas. Escritoras afro-brasileiras como Conceição Evaristo, Miriam Alves, Esmeralda Ribeiro, Elisa Lucinda, Cristiane Sobral, dentre outras, têm discutido a respeito dessa questão nos seus textos poéticos e/ou ficcionais. Esse é o tema central do conto "Pixaim", de Cristiane Sobral. Publicado originalmente nos Cadernos Negros, volume 24, no ano 2000, "Pixaim" voltou a ser editado na antologia Espelhos, miradouros e dialéticas da percepção (2011), obra individual da autora.

\footnotetext{
${ }^{1}$ HOOKS. Alisando o nosso cabelo.
} 
O título "Pixaim" já diz muito sobre o conteúdo abordado na história. Pixaim é uma palavra utilizada com recorrência para caracterizar os cabelos crespos, muito frisados, de pessoas negras. Na maioria das vezes em que essa palavra é proferida, ela tem uma significação negativa. Ela é utilizada no intuito de ofender, diminuir, agredir a outra pessoa. Cabelo pixaim é o cabelo que não é considerado "bom". Uma criança negra dificilmente crescerá sem ter ouvido, em algum momento de sua infância, que o seu cabelo crespo é duro, ruim. É, portanto, um cabelo de pixaim. ${ }^{2}$ A professora e antropóloga Nilma Lino Gomes, em uma pesquisa na qual estudou a influência do cabelo na construção identitária das pessoas negras, concluiu que:

O papel desempenhado pela dupla cabelo e cor da pele na construção da identidade negra [...] sobretudo do cabelo, na maneira como o negro se vê e é visto pelo outro, até mesmo para aquele que consegue algum tipo de ascensão social, está presente nos diversos espaços e relações nos quais os negros se socializam e se educam: a família, as amizades, as relações afetivo-sexuais, o trabalho e a escola. Para esse sujeito, o cabelo carrega uma forte marca identitária e, em algumas situações, é visto como marca de inferioridade. ${ }^{3}$

No conto de Cristiane Sobral, o cabelo crespo da protagonista é visto como um símbolo de inferioridade, não por ela, mas por sua mãe. A mulher começa a alisar o cabelo da filha desde a mais tenra infância com o intuito de deixá-la mais "bonitinha". Logo no início do conto, a

\footnotetext{
${ }^{2}$ No artigo "Nega do cabelo duro, qual é o pente que te penteia?", resultado de uma pesquisa que levantou dados sobre as denominações referentes ao cabelo das pessoas negras, os pesquisadores chegaram à alarmante conclusão de que "das 49 (quarenta e nove) denominações diferentes para cabelo crespo, 21 (vinte e uma) fazem referência à falta de limpeza, higiene, falta de zelo ou descuido. Das mesmas 49 (quarenta e nove), 07 (sete) fazem referência a animais como macaco, rato, cupim, leão, chegando a alusões escatológicas como bosta de pássaro. De todas, 05 (cinco) fazem referência a materiais como esponjas de aço, ferro, alumínio e arame, numa alusão clara que justifica o "cabelo duro". Apenas 06 (seis) não são pejorativas, como anelado, crespo, ondulado, cacheado, afro e black power". (ARAÚJO; SANTANA; KATRIB. Nega do cabelo duro, qual é o pente que te penteia?, p.8-9).

${ }^{3}$ GOMES. Educação, identidade negra e formação de professores/as: um olhar sobre o corpo negro e o cabelo crespo", p. 173.
} 
personagem-narradora relembra o primeiro momento em que os seus cabelos crespos foram atacados:

Os ataques começaram quando fui apresentada a uns pentes estranhos, incrivelmente frágeis, de dentes finos, logo quebrados entre as minhas madeixas acinzentadas. Pela primeira vez, ouço a expressão “cabelo ruim". Depois, uma vizinha disse a minha mãe que lutava todos os dias para me pentear e me deixar bonitinha como as outras crianças, que tinha uma solução para amolecer a minha "carapinha dura". ${ }^{4}$

As estratégias narrativas utilizadas por Sobral descrevem o ato de pentear o cabelo como um duelo entre mãe e filha. O sentido de tal combate se reforça com o uso de termos, tais como: "ataque", "luta", "rebelde". Nessa guerra que a mãe trava com a filha para domar as suas carapinhas insubordinadas, a menina ouve, pela primeira vez, a expressão "cabelo ruim". A violência imposta faz com que a narradora, ainda criança, desenvolva resiliência, adquirindo "uma estranha capacidade de regeneração e de ter ideias próprias". ${ }^{5}$ Esta atitude insubmissa da personagem infantil, que, mesmo com as suas raízes podadas, não se deixa sucumbir, será um fator importante no processo constitutivo de sua identidade negra. A reação da menina se mostra em consonância com as reflexões de Nilma Lino Gomes. A pesquisadora ressalta que

[é] importante lembrar que a identidade construída pelo negro se dá não só por oposição ao branco, mas, também, pela negociação, pelo conflito e pelo diálogo com este. As diferenças implicam processos de aproximação e distanciamento. Nesse jogo complexo, vamos aprendendo, aos poucos, que as diferenças são imprescindíveis na construção da nossa identidade. ${ }^{6}$

À medida que a narradora do conto cresce, ela vai se tornando mais consciente de suas diferenças: "Eu sabia que não era igual às outras crianças. E que não podia ser tratada da mesma forma. Mas como

\footnotetext{
${ }^{4}$ SOBRAL. Espelhos, miradouros, dialéticas da percepção, p. 21.

${ }^{5}$ SOBRAL. Espelhos, miradouros, dialéticas da percepção, p. 21.

${ }^{6}$ GOMES. Educação, identidade negra e formação de professores/as: um olhar sobre o corpo negro e o cabelo crespo, p. 172.
} 
dizer isso aos outros?". ${ }^{7}$ Pelas pistas deixadas pela narradora, ficamos sabendo que ela tinha consciência da sua negritude e que o seu tipo de cabelo não era discordante com a sua identidade. No prosseguimento do texto, a narradora revela que a sua mãe era branca e o seu pai era negro. Sendo branca e tendo uma menina negra, mais escura do que os outros filhos, a mulher vive o conflito de uma relação interracial, metaforizada no conto pela luta que trava contra o cabelo da filha. Podemos inferir que esta conduta da mãe da personagem, "ao invés de ser um vetor para desconstrução e reelaboração do racismo, é o espaço onde o mesmo é reposto, já que a raça e o racismo modulam os vínculos afetivos". ${ }^{8}$ Esse comportamento da personagem adulta motiva a percepção da criança de que a mãe, embora lhe amasse, não sabia lidar com as suas diferenças. ${ }^{9}$

Um aspecto que chama a atenção no conto é o fato da protagonista não ser nomeada. Entendemos essa estratégia como uma tentativa da autora representar, através da personagem, todas as meninas negras que sofrem com a violência de terem os cabelos crespos forçosamente alisados. Diante da brutalidade da violência racista, a menina vai perdendo a sua capacidade de lutar: "Eu já não resistia e comecei a acreditar no que diziam. Todos os dias eram tristes e eu tinha a certeza de que apesar do cabelo circunstancialmente "bom", eu jamais seria branca". ${ }^{10}$

Outra estratégia literária utilizada por Sobral se refere à posição da narradora do conto. No primeiro e último parágrafos da história, temos uma voz narrativa onisciente, em terceira pessoa, que apenas narra os fatos, sem participar diretamente da história. Do segundo parágrafo ao penúltimo, a história é contada em primeira pessoa. Ao valer-se da narração em terceira pessoa, no início e no final do conto, aparentemente, a intenção da voz narrativa é manter certa distância daquilo que conta, interessada apenas em situar o leitor nos contextos específicos nos quais a história se passa, respectivamente, Rio de Janeiro e Brasília.

Ainda nos referindo aos aspectos estéticos e estilísticos que marcam o processo de construção narrativa do conto "Pixaim", podemos notar que uma das estratégias utilizadas por Cristiane Sobral para

\footnotetext{
${ }^{7}$ SOBRAL. Espelhos, miradouros, dialéticas da percepção, p. 21.

${ }^{8}$ SCHUCMAN; GONÇALVES. Racismo na família e a construção da negritude: embates e limites entre a degradação e a positivação na constituição do sujeito, p. 68 . ${ }^{9}$ SOBRAL. Espelhos, miradouros, dialéticas da percepção, p. 21.

${ }^{10}$ SOBRAL. Espelhos, miradouros, dialéticas da percepção, p. 24.
} 
provocar um efeito profundo no(a) leitor(a) é o fato de a violência racial ser abordada na perspectiva de uma criança. A violência descrita no ponto de vista do olhar infantil, aparentemente, alcança uma dimensão maior porque a criança vitimada parece incapaz de se defender. Isso faz com que o(a) leitor(a) do texto, na maior parte das vezes, sinta uma grande empatia pela personagem violentada, tornando-se mais sensível ao problema que está sendo abordado nas linhas da ficção. Colocar na fala de uma criança palavras, tais como: "tortura, pavor, chibatadas, aprisionada" cria um incômodo, pois elas parecem não combinar com a descrição do universo infantil. Quando essas palavras são pronunciadas pela narradora de dez anos, a impressão que temos é de que há uma desarmonia entre o que é falado e aquela quem fala.

De tanto ouvir expressões racistas, os pensamentos e ações da protagonista do conto "Pixaim" começam a ficar limitados. Nesse contexto, a mãe, paradoxalmente, mesmo amando a filha, é também a grande responsável por reproduzir a agressão contra a criança. Ao descrever a maneira como a mãe cuidava do seu cabelo na tentativa de transformá-la, a personagem-narradora se vale de imagens que remetem ao processo de escravização dos africanos. O fragmento abaixo destacado comprova essa assertiva:

Jamais esquecerei a minha primeira sessão de tortura. Era um bonito dia de sol e céu azuladíssimo. Eu brincava no quintal, distraída, quando ouvi o chamado grave de minha mãe, já com a panela quente nas mãos, e pensei com pavor na foto da mulher com cabelo alisado. Nesse momento tive a certeza de que mamãe queria me embranquecer! Era a tentativa de extinção do meu valor! Chorei, tentei fugir e fui capturada e premiada com chibatadas de vara de marmelo nos braços. ${ }^{11}$

Enclausurada em uma máscara que a mãe lhe obriga a usar e presa a uma dor inscrita em seu corpo, a jovem personagem de "Pixaim" é subtraída de "todo o infinito potencial de criatividade, beleza e prazer que é capaz de produzir". ${ }^{12}$ Além de não poder assumir as suas raízes crespas, símbolo mais representativo de sua identidade negra, a menina

${ }^{11}$ SOBRAL. Espelhos, miradouros, dialéticas da percepção, p. 23.

${ }^{12}$ COSTA. Da cor ao corpo: a violência do racismo, p. 9. 
também é proibida de viver plenamente a sua infância. A mãe limitava os movimentos que a filha poderia fazer durante as brincadeiras para ela não correr o risco de "transpirar e encolher o cabelinho". ${ }^{13}$ Certa de que o padrão de beleza eurocêntrico é o mais adequado para a criança, a mãe faz um elogio à filha somente quando esta se apresenta com um cabelo semelhante ao das mulheres brancas:

Dia seguinte. Minha mãe me chamou inesperadamente carinhosa e me colocou frente ao espelho. Pela primeira vez disse:

- Você está bonita! [...] Eu olhei e não acreditei. Já tinha a expressão da mulher da caixa de henê. ${ }^{14}$

Cremos que o pensamento da mãe da narradora funciona de acordo com os mecanismos que engendram as relações raciais na sociedade brasileira. Em um importante estudo sobre a manifestação do racismo em famílias interraciais, a pesquisadora e psicóloga social Lia Vainer Schucman concluiu que, no Brasil:

Quanto mais escura a cor da pele de um indivíduo, mais perto da ideia de raça negra estereotipada e estigmatizada pelo racismo moderno ele está localizado, e quanto mais perto da cor de pele branca, mais status e privilégios ele ganha. ${ }^{15}$

De tal forma, a mãe da personagem do conto "Pixaim", convencida que a identidade branca seria mais apropriada para a filha, tenta a todo custo distanciar a menina dos elementos que a aproximem de sua negrura. Ao agir dessa forma, de certa maneira, ela tenta "legitimar os significados positivos ligados ao branco e os negativos ligados ao negro, reafirmando que cabelo liso é branco, e que cabelo liso é mais bonito". ${ }^{16}$ Talvez, sem ter compreensão de que o alisamento imposto é uma experiência traumatizante para a filha, a mulher aprisiona a menina dentro da identidade que considera superior. Podemos tentar compreender

${ }^{13}$ SOBRAL. Espelhos, miradouros, dialéticas da percepção, p. 23.

${ }^{14}$ SOBRAL. Espelhos, miradouros, dialéticas da percepção, p. 24.

${ }^{15}$ SCHUCMAN; FACHIM. A cor de Amanda: identificações familiares, mestiçagem e classificações raciais brasileiras, p.184.

${ }^{16}$ SCHUCMAN; MANDELBAUM; FACHIM. Minha mãe pintou meu pai de branco: afetos e negação da raça em famílias interraciais, p.452. 
essa relação conflituosa entre as duas personagens com a contribuição do filósofo indiano Amartya Sen. Em seu livro Identidade e violência (2015), Sen faz uma ampla discussão a respeito do perigo das pessoas serem compartimentadas em grupos identitários determinados, num apelo ao discurso de que somos todos iguais, quando, de fato, somos todos diferentes. De acordo com Sen:

Muitos dos conflitos e da barbárie no mundo são sustentados pela ilusão de uma identidade única e sem alternativa. A arte de fabricar o ódio assume a forma de uma invocação do poder mágico de uma identidade supostamente predominante que afoga outras filiações e, em uma forma convenientemente belicosa, pode também subjugar qualquer simpatia humana ou bondade natural que possamos normalmente ter. $\mathrm{O}$ resultado pode ser uma violência doméstica rudimentar ou engenhosos modos de violência e terrorismo em escala global. [...] O incentivo adequado, um sentimento reforçado de identidade com um grupo de pessoas pode ser transformado em poderosa arma para brutalizar o outro. ${ }^{17}$

Os aprisionamentos identitários podem tornar as pessoas incapazes de respeitarem as diferenças, provocando um desequilíbrio nas relações que gera micro e macro violências. No caso específico do conto "Pixaim", a mãe da narradora, mesmo que inconscientemente, acredita que os seus traços característicos de pessoa branca são superiores aos da filha negra. Armada com múltiplos instrumentos de "tortura capilar", tais como: o pente inadequado, o creme alisante, os bobs cheios de grampos, o ferro quente, a mãe violenta a filha. Notemos que estes instrumentos utilizados para mudar a textura do cabelo da menina, de alguma forma, representam um aumento na gradação da violência. Em um primeiro momento, a mulher tenta amansar a rebeldia do cabelo da criança com "pentes estranhos, incrivelmente frágeis, de dentes finos", ${ }^{18}$ sem obter sucesso na ofensiva, ela vai experimentando novos métodos de ataque aos fios rebeldes, até deixar uma marca na filha que a faria lembrar para sempre da violência praticada contra ela:

${ }^{17}$ SEN. Identidade e violência: a ilusão do destino, p. 13.

${ }^{18}$ SOBRAL. Espelhos, miradouros, dialéticas da percepção, p. 21. 
Minha mãe decidiu que o meu pixainho tinha que crescer e aparecer. Lembro do pente quente que se usava na época, para fazer o crespo ficar "bom", e da marca do pente quente que tatuou meu ombro esquerdo, por resistir àquela imposta transformação. Era domingo, íamos todos a uma festa, e eu tinha que ficar bonita como as outras. No caminho, caiu uma chuva, dessas de verão, e em poucos minutos, houve o milagre, pois a água anulou o efeito do pente. Eu chorava porque achava que o meu cabelo nunca voltaria ao normal, e minha mãe ficou brava porque eu estava parecendo comigo, de um jeito nunca antes visto! ${ }^{19}$

No excerto acima, além do efeito do ferro quente, outro efeito interessante de ser observado é o da água. Se antes a água havia penetrado friamente no couro cabeludo da menina, provocando uma sensação de dor e contribuindo para intensificar o efeito da violência sobre as suas raízes crespas, agora, a água que cai da chuva funciona como um elemento que anula o efeito do pente quente no cabelo da personagem. Nesse momento, a narradora destaca o contraste das reações da mãe e da filha: enquanto a criança chora aliviada por perceber que a água operara o milagre de fazer o seu cabelo voltar a ser como era antes de ser transformado; a sua mãe se enraivece ao notar que o cabelo natural da menina fazia com que ela se parecesse consigo mesma de "um jeito nunca antes visto". ${ }^{20}$

A mãe da personagem-narradora não consegue enxergar a filha para além da cor de sua pele e do seu cabelo crespo. A menina sabia que era impossível convencer a mãe, irmãos e vizinhos a aceitarem-na em sua diferença. Essa atitude da protagonista remete, mais uma vez, ao texto Identidade e violência, de Amartya Sen. Na perspectiva desse estudioso, "mesmo quando está claro o modo como desejamos ver a nós mesmos, ainda podemos ter dificuldades em conseguir persuadir os outros a vernos da mesma maneira". ${ }^{21}$ De tal modo, ao se recusar a alisar o cabelo, a personagem deixa ainda mais evidente o seu fenótipo negro. A negrura escancarada que tanto orgulha a menina, aumenta a rejeição da mãe e dos irmãos em relação a ela.

\footnotetext{
${ }^{19}$ SOBRAL. Espelhos, miradouros, dialéticas da percepção, p. 22.

${ }^{20}$ SOBRAL. Espelhos, miradouros, dialéticas da percepção, p. 22.

${ }^{21}$ SEN. Identidade e violência: a ilusão do destino, p. 24.
} 
Como já observamos, o racismo do qual a narradora é vítima se manifesta justamente no espaço em que ela deveria receber proteção: o ambiente familiar. Os estudos realizados por Lia Schucman, em parceria com outras e outros pesquisadoras/es, os quais estamos destacando no decorrer da análise do conto "Pixaim", nos permitem inferir que a situação encenada na narrativa de Cristiane Sobral apresenta-se de maneira ainda mais violenta no mundo real. De acordo com a pesquisa coordenada por Schucman, a prática de racismo por membros da própria família, busca negar, portanto,

[...] não a cor real do outro, mas sim todo o significado racista de nossa sociedade, que recairá sobre o outro quando "chegar a hora" de ele se entender como negro. É aí que reside o paradoxo da negação, pois o que parece uma solução contra o racismo acaba por reafirmá-lo e reforçá-lo. Para ficar longe do significado racista sobre "ser negro", estes sujeitos negam a negritude e perdem a possibilidade de desconstruir os estereótipos negativos atrelados ao signo 'negro'. ${ }^{22}$

No seio da família da narradora, a hierarquização das raças é o que define o nível de afeto da mãe e dos irmãos em relação a ela. "Isto mostra, precisamente, que diferenças na cor em pessoas de uma mesma família representam, no imaginário social, uma quebra dos laços sanguíneos". ${ }^{23}$ $\mathrm{O}$ fragmento destacado a seguir, revela o momento em que, depois de sucessivas violências, a protagonista de "Pixaim" finalmente compreende o que movia a mãe a praticar tantas agressões contra ela:

Foi aí que eu tive uma inesperada luz. Minha mãe queria me embranquecer para que eu sobrevivesse à cruel discriminação de ser o tempo todo rejeitada por ser diferente [...]. Eu era a ovelha mais negra, rebelde por excelência, a mais escura e a que tinha o cabelo "pior". Às vezes, eu acreditava mesmo que o meu nome verdadeiro era pixaim. ${ }^{24}$

\footnotetext{
${ }^{22}$ SCHUCMAN; MANDELBAUM; FACHIM. Minha mãe pintou meu pai de branco: afetos e negação da raça em famílias interraciais, p. 451.

${ }^{23}$ SCHUCMAN; GONÇALVES. Racismo na família e a construção da negritude: embates e limites entre a degradação e a positivação na constituição do sujeito, p. 77. ${ }^{24}$ SOBRAL. Espelhos, miradouros, dialéticas da percepção, p. 24.
} 
O excerto acima revela uma questão interessante no sentido de analisarmos o modo como o racismo se manifesta em famílias interraciais. É possível dizer que uma pessoa racista pode se relacionar afetivamente com uma pessoa do grupo racial que considera inferior e, nem por isso, deixar de ser racista. A mãe da narradora do conto, por exemplo, "jamais pensara na dificuldade de ter uma criança negra, mesmo tendo casado com um homem negro". ${ }^{25}$ Pensamos que a mulher mantém tão entranhada em si a ideia da superioridade da sua cor em relação à do marido, que seria impensável imaginar que uma filha dos dois pudesse ter os traços fenotípicos predominantemente da raça negra. Dessa forma, "ao negar a negritude da menina, a mãe mantém e legitima os significados negativos construídos em nossa sociedade sobre o negro, sem precisar rever, ressignificar e desconstruir o racismo em que foi socializada". ${ }^{26}$

Ao tentar embranquecer a filha, a mãe, de um modo bastante questionável, demonstra querer proteger a criança da discriminação que ela sofreria por ser negra. Contudo, as suas atitudes permitem entrever que o seu vínculo com a filha podia se fortalecer, caso a menina aceitasse que a sua identidade negra fosse anulada ou suavizada. "O recado passado de mãe para filha nesta mensagem é: se você se embranquecer, será amada". ${ }^{27}$ Nesse contexto, é possível dizer que a mãe branca se apega aos estereótipos negativos sobre o negro, buscando a todo custo adequar a imagem da filha a um modelo mais semelhante à sua figura.

A obsessão da mãe em enquadrar o cabelo da filha dentro da estética que define como bela, provoca traumas que marcarão para sempre a vida da narradora. Contudo, a despeito de uma infância violenta, a despeito do racismo sofrido, a protagonista da história transforma-se em uma mulher que valoriza as suas raízes, mantendo os fios enrolados e a mente aberta para as coisas boas que a vida pode lhe oferecer:

Quinze anos depois, em Brasília, no coração do planalto central, é segunda-feira, dia de começos. Uma mulher madura de olhar doce e fértil vê sua imagem no espelho e ajeita com cuidado as tranças corridas, a contemplar com

\footnotetext{
${ }^{25}$ SOBRAL. Espelhos, miradouros, dialéticas da percepção, p. 24.

${ }^{26}$ SCHUCMAN; MANDELBAUM; FACHIM. Minha mãe pintou meu pai de branco: afetos e negação da raça em famílias interraciais, p. 446-447.

${ }^{27}$ SCHUCMAN; GONÇALVES. Racismo na família e a construção da negritude: embates e limites entre a degradação e a positivação na constituição do sujeito, p. 74 .
} 
satisfação a história escrita em seu rosto e a beleza que os pensamentos dignos conferem à sua expressão. É uma mulher livre, vencedora de muitas batalhas interiores, que se prepara para a vida lutando para preservar a sua origem, pois sabe que é a única herança verdadeira que possui. Ela aprendeu e jamais esquecerá. A gente só pode ser aquilo que é. ${ }^{28}$

Consciente da sua história e de suas raízes, a protagonista do conto demonstra alegria em poder ser aquilo que é. Ela enxerga a vida com olhos férteis, pronta para espalhar sementes e colher os bons frutos de sua semeadura. Ela entra "em contato com a história, memória e herança cultural africana presente na formação cultural afro-brasileira". ${ }^{29}$ Ao se referir à "história escrita em seu rosto", a narradora reconhece, nos seus traços, a história de suas antepassadas que também tiveram a sua identidade brutalmente violentada. É possível dizer que a personagem resgata as suas origens ancestrais, pois aprendeu que quando sabemos de onde viemos, fica mais fácil escolher novos caminhos.

Nessa narrativa em que a violência racial mostra uma de suas facetas mais ferozes, nesse texto em que passado e presente se encontram, as palavras têm uma cadência. Os pequenos parágrafos, as frases curtas e marcantes, os vocábulos certeiros, todos esses elementos dão um ritmo diferente ao conto de Cristiane Sobral. O fragmento do texto, abaixo destacado, é um exemplo dessa rede de significados construída pela prosa-poética da autora afro-brasileira:

O negro sempre foi para mim o desconhecido, a fantasia, o desejo. Cresci tentando ser algo que eu não conhecia, mas que intuitivamente sabia ser meu, só meu... O meu cabelo era a carapaça das minhas ideias, o invólucro dos meus sonhos, a moldura dos meus pensamentos mais coloridos. Foi a partir do meu pixaim que percebi todo um conjunto de posturas a apontar para a necessidade social de me enquadrar num padrão de beleza, de pensamento e opção de vida. ${ }^{30}$

\footnotetext{
${ }^{28}$ SOBRAL. Espelhos, miradouros, dialéticas da percepção, p. 25.

${ }^{29}$ GOMES. Educação, identidade negra e formação de professores/as: um olhar sobre o corpo negro e o cabelo crespo, p. 180.

${ }^{30}$ SOBRAL. Espelhos, miradouros, dialéticas da percepção, p. 25
} 
No conto "Pixaim", o cabelo crespo, mais do que um elemento estético, torna-se um símbolo de resistência. Se nos atentarmos às palavras utilizadas pela narradora para fazer referência ao seu cabelo, podemos deixar mais explícita essa ideia. "Carapaça", "invólucro", "moldura", todas essas expressões transmitem uma ideia de segurança, de proteção, de abrigo. A partir do momento em que a personagem decide assumir o seu cabelo tal qual ele é, ressignifica o sentido dado ao termo carapaça. A carapaça não a aprisiona, ela apenas protege suas ideias, permitindo que elas voem sem medo. Liberta da violência da mãe, a protagonista consegue se enxergar fora do padrão de beleza imposto em sua infância. Ela se enxerga fora do ideal do branco e da brancura que circulava dentro do seu contexto familiar. A postura transgressora da personagem dialoga com o pensamento de Neusa Santos Souza. De acordo com a psicanalista:

A possibilidade de construir uma identidade negra tarefa eminentemente política - exige como condição imprescindível, a contestação do modelo advindo das figuras primeiras - pais ou substitutos - que lhe ensinam a ser uma caricatura do branco. Rompendo com este modelo, o negro organiza as condições de possibilidade que lhe permitirão ter um rosto próprio. ${ }^{31}$

Depois de conseguir romper o modelo da "caricatura do branco", ensinado pela mãe, afirmando-se como negra, a personagem do conto ressignifica a expressão "pixaim". A palavra que antes lhe remetia a um sentimento de dor, passa a ser utilizada como símbolo de prazer. Consciente do seu cabelo crespo como característica indissociável da sua identidade negra, a protagonista do conto se refere ao cabelo como "meu pixaim". O uso do pronome possessivo demonstra que a assunção dos fios em formato de carapinhas torna-se um símbolo de insubmissão da narradora. Ela entende que o seu cabelo não precisa ser domado para atender às expectativas dos outros. Ela valoriza o seu pixaim, assim como valoriza qualquer outro órgão do seu corpo. Dessa forma, podemos dizer que, "o grau em que nos sentimos cômodas com o nosso cabelo reflete os nossos sentimentos gerais sobre o nosso corpo". ${ }^{32}$

31 SOUZA. Tornar-se negro: as vicissitudes da identidade do negro brasileiro em ascensão social, p. 77.

${ }^{32}$ HOOKS. Alisando o nosso cabelo. 
Ao assumir o seu cabelo crespo, a protagonista do conto "Pixaim" aprende a valorizar ainda mais a sua identidade negra e as suas raízes ancestrais. Raízes crespas que não mais alisará, a não ser que faça isso por escolha, não mais por imposição. Aprende a construir suas próprias molduras. Aprende a se mirar em outros espelhos. Aprende a olhar e se ver. Aprende que, ao buscar espelhos que refletem a sua imagem, pode enxergar neles não apenas a si mesma, mas a todas as suas ancestrais, mulheres negras, violentadas por ser aquilo que eram, mas que seguiram, resilientes, sendo aquilo que são.

\section{Referências}

ARAÚJO, Maria de Lourdes Bertoni; SANTANA, Wylliane Estelaide Paixão de; KATRIB, Cairo Mohamad Ibrahim. Nega do cabelo duro, qual é o pente que te penteia?. CONGRESSO Internacional de História: Cultura, Sociedade e Poder, 4., Jataí, 2014. Anais eletrônicos... Jataí: UFG, 1014. p. 1-10. Disponível em: <http://www.congressohistoriajatai. org/anais2014/Link\%20(180).pdf>. Acesso em: 5 mar. 2018.

COSTA, Jurandir Freire. Da cor ao corpo: a violência do racismo. In: SOUSA, Neusa Santos. Tornar-se negro: as vicissitudes da identidade do negro brasileiro em ascensão social. Rio de Janeiro: Edições Graal, 1983. p.135-153.

GOMES, Nilma Lino. Educação, identidade negra e formação de professores/as: um olhar sobre o corpo negro e o cabelo crespo. Educação e Pesquisa, São Paulo, v. 29, n. 1, p. 167-182, jan./jun. 2003. Disponível em: <http://www.scielo.br/pdf/ep/v29n1/a12v29n1.pdf $>$. Acesso em: 1 mar. 2018.

HOOKS, bell. Alisando o nosso cabelo. Tradução de Lia Maria dos Santos. Geledés, [S.1.], 10 jun. 2014. Disponível em: <https://www. geledes.org.br/alisando-o-nosso-cabelo-por-bell-hooks/>. Acesso em: 8 fev. 2017.

SCHUCMAN, Lia Vainer; FACHIM, Felipe Luis. A cor de Amanda: identificações familiares, mestiçagem e classificações raciais brasileiras. Interfaces Brasil/Canadá, Florianópolis, Pelotas, São Paulo, v. 16, p. 182-205, n. 3, 2016. Disponível em: <https://periodicos.ufpel.edu.br/ojs2/ index.php/interfaces/article/view/10001/6763>. Acesso em: 9 jan. 2018. 
SCHUCMAN, Lia Vainer; GONÇALVES, Mônica Mendes. Racismo na família e a construção da negritude: embates e limites entre a degradação e a positivação na constituição do sujeito. Odeere, Jequié, BA, v. 2, n. 4, p. 61-83, dez. 2017. Disponível em: <http://periodicos2.uesb.br/index. php/odeere/article/view/2366. . . Acesso em: 10 jan. 2018.

SCHUCMAN, Lia Vainer; MANDELBAUM, Belinda; FACHIM, Felipe Lui. Minha mãe pintou meu pai de branco: afetos e negação da raça em famílias interraciais. Revista de Ciências Humanas, Florianópolis, v. 51, n. 2, p. 439-455, jul./dez. 2017. Disponível em: <https://periodicos.ufsc.br/ index.php/revistacfh/article/view/2178-4582.2017v51n2p439/35691>. Acesso em: 9 jan. 2018.

SEN, Amartya. Identidade e violência: a ilusão do destino. Tradução de José Antônio Arantes. São Paulo: Iluminuras, Itaú Cultural, 2015.

SOBRAL, Cristiane. Espelhos, miradouros, dialéticas da percepção. Brasília: Editora Dulcina, 2011.

SOUZA, Neusa Santos. Tornar-se negro: as vicissitudes da identidade do negro brasileiro em ascensão social. Rio de Janeiro: Edições Graal, 1983.

Recebido em: 29 de junho de 2018. Aprovado em: 4 de dezembro de 2018. 